\title{
Periodicities of photosynthesis and cell division: behavior of phase-lagged replicate cultures of Ditylum brightwellii in a diurnally varying photic regime
}

\author{
L. W. Harding, Jr. and J. F. Heinbokel \\ Chesapeake Bay Institute, The John Hopkins University, 4800 Atwell Road, Shady Side, Maryland 20764, USA
}

\begin{abstract}
Diel periodicities of photosynthetic capacity (light-saturated photosynthesis $=\mathrm{P}_{\max }$ ) and cell division were studied for the marine centric diatom Ditylum brightwellii grown in a light environment that varied in intensity. A method was used to phase-lag replicate cultures of $D$. brightwellii to a light-dark schedule by offsetting subjective dawn at successive $1 \mathrm{~h}$ intervals. Control experiments were conducted using a more traditional protocol of around-the-clock sampling. Both approaches documented the periodicities of $P_{\max }$ and cell division for this species in a diurnally varying light cycle, demonstrating the usefulness of the phase-lagging technique in reproducing time-dependent patterns in photosynthesis and growth. Comparative data on photosynthetic periodicity of $D$. brightwellii in a photic regime of constant intensity are presented from earlier work. An explanation is offered for differences in amplitude and timing of photosynthetic rhythms, focusing on light loading and the coupling of integral photosynthetic performance to the maximum growth rate.
\end{abstract}

\section{INTRODUCTION}

Diel periodicities of photosynthesis and cell division are well known for the large centric diatom Ditylum brightwellii (West) Grun grown in light-dark (LD) cycles (Eppley et al., 1967; Paasche, 1968; Chisholm et al., 1978, 1980; Nelson and Brand, 1979; Harding et al., 1981a; Chisholm, 1981). The timing of cell division in D. brightwellii shows significant variability (review: Chisholm, 1981). Division occurred mainly in the light portion of LD schedules in studies by Eppley et al. (1967), Paasche (1968), and Chisholm et al. (1978), while Richman and Rogers (1969) reported that division took place in the dark period. Differences in timing can apparently be elicited by environmental conditions, specifically the temperature and irradiance regime used to grow cultures (Chisholm et al., 1980). Chisholm (1981) concluded that division phasing in diatoms appears to be 'forced' by environmental variables, rather than simply entrained by the LD cycle, as appears to be the case in other taxa of phytoplankton.

Timing during the day of maximum photosynthetic capacity in Ditylum brightwellii also appears to vary, depending on the growth phase of cells in batch cul- tures (Harding et al., 1981b). Coupling of physiological state to environmental conditions has been suggested as affecting timing and amplitude of photosynthetic peaks, but confirming evidence to support this hypothesis is unavailable at present. The rhythm in photosynthesis also appears to be labile, similar to that in division, and the arguments posed by Chisholm (1981) concerning control of timing may well be applicable to periodicity of photosynthesis.

For phytoplankton in nature, similar variability in the timing of photosynthetic maxima has been noted, with the realization that such uncertainty will complicate efforts to measure daily rates of primary production in these natural assemblages (cf. Harding et al., $1982 a, b)$. Several explanations have been offered in the past for this variability (review: Sournia, 1974). For example, Doty (1959) implicated latitudinal differences in photoperiod as the cause of morning versus afternoon maxima in carbon assimilation, and Malone (1971) later suggested that nutrient availability, cellsize distribution, and storage capacity may control the time of day that phytoplankton assemblages exhibit maximal photosynthesis. Both suggestions are generally consistent with laboratory findings, but few data 
are available that document a cause and effect relationship for environmental forcing of time-dependent responses in phytoplankton physiology.

There are several reasons for this lack of documentation. First, most studies of periodicity have been conducted using LD schedules which do not vary in intensity during the light portion of the cycle. This simplification makes work with aigal cultures relatively routine, but may not adequately address the role of light. That is, light serves not only as an 'on/off' cue ('Zeitgeber') in phasing cultures, but also directly drives carbon assimilation and growth. Removing natural variations in intensity from laboratory cultures can be expected to alter the cells' physiological responses, and may invalidate extrapolation of laboratory results to the field. Second, most studies of photosynthetic rhythms do not have sufficient temporal resolution to allow detection of shifts in timing that accompany changes in environmental conditions. The relatively low frequency of measurements (i.e. every 4 to 6 h) generally obtained in studies of periodicity is simply insufficient to detect shifts (cf. Prézelin et al., 1977; Prézelin and Ley, 1980). Third, because changes in photosynthetic characteristics associated with environmental factors (e.g. light, temperature) can resemble and even overlap those that are rhythmic, it can be difficult to sort innate from forced responses. For example, photoadaptation involves quantitative shifts in the photosynthesis-irradiance (P-I) relationship that can be confused with periodic or rhythmic changes (Harding et al., 1983).

The use of phase-lagged replicate cultures offers a potentially convenient solution to these problems. A culture device that phases cultures to distinct LD schedules and also provides a diurnally varying photic regime was used recently to study photoadaptation and diel periodicity of photosynthesis in the dinoflagellate Prorocentrum mariae-lebouriae (see Harding et al., 1983). This approach proved successful in simulating diurnal variations in sunlight intensity, in giving improved temporal resolution in photosynthetic measurements by providing a set of replicate cultures phased to offset LD schedules successively, and in allowing the separation of rhythmic from directional physiological responses.

The purpose of the work with Ditylum brightwellil described in this paper was to document the usefulness of this culture approach in studying time-dependent patterns in photosynthesis and cell division. A comparison was made of patterns in photosynthetic capacity $\left(P_{\max }\right)$ and cell division using both single and phaselagged sets of batch cultures of $D$. brightwellii that were grown in a diurnally varying light regime. The results demonstrate the usefulness of the phase-lagging technique by showing how time-dependent phy- siological patterns in single batch cultures monitored around-the-clock can be reproduced by making measurements on a set of individually-phased replicate cultures representing all hours in the day. The patterns of photosynthetic carbon assimilation in this irradiance regime are also compared to those of a previous study, and implications of differences are discussed in the context of light loading and an optimal strategy for carbon metabolism.

\section{MATERIALS AND METHODS}

\section{Culture technique}

Ditylum brightwellii was grown in ' $\mathrm{f} / 2$ ' medium (Guillard and Ryther, 1962) at $15^{\circ}$ on a LD 12:12 cycle in which irradiance was varied to more realistically simulate natural conditions (Fig. 1). The approach used to phase-lag replicate cultures has been described by Harding et al. (1983). Briefly, the method uses a device, the 'wheel', to offset the beginning of the light period at $1 \mathrm{~h}$ intervals around a stationary, circular enclosure that is divided into 24 equal-sized culture compartments. Phasing of individual cultures is effected by a rotating shade that undergoes 1 complete revolution $\mathrm{d}^{-1}$. Half the rotating shade is fitted with layers of neutral density screening in a sequentially decreasing, then increasing number, while the other half of the shade is opaque. As the shade rotates between a light source ('cool white' fluorescent lamps) and culture compartments with transparent bottoms, the light intensity provided to overlying cultures varies, controlled by the transmission of light through the

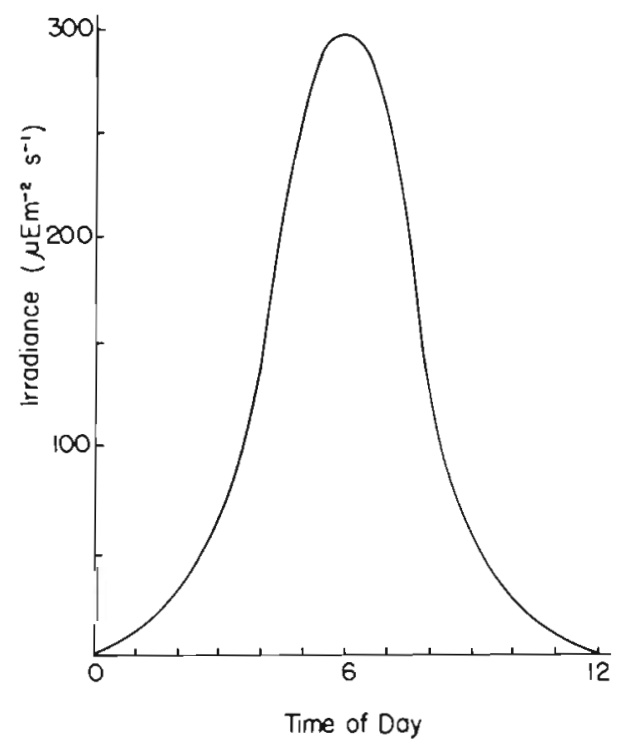

Fig. 1. Ditylum brightwellii. Light cycle provided to phaselagged replicate cultures 
shade sectors. The individual culture compartments are thereby independently phased to a distinct and defined LD cycle, and each receives the same total irradiance in a day-night cycle, at an intensity that varies diurnally to simulate the natural sunlight cycle.

\section{Experimental design}

Ditylum brightwellii was obtained from the culture collection of the Institute of Marine Resources, Scripps Institution of Oceanography (La Jolla, California, USA). Cultures of $D$. brightwellii were grown on the 'wheel' for $5 \mathrm{~d}$ prior to commencing experiments. This period of time was sufficient to phase-shift the cultures to new LD schedules. Cultures were in mid-logarithmic phase of growth throughout the experiments. Measurements of photosynthetic capacity $\left(\mathrm{P}_{\max }\right)$, cell numbers, chlorophyll (chl a) concentration, and cell division stages were then made over a $3 \mathrm{~d}$ period. The experiments consisted of 2 parts. In one set, beginning at 08.00 on Day 1, samples were withdrawn from the culture in a single, randomly selected compartment (\#17) at $2 \mathrm{~h}$ intervals for $24 \mathrm{~h}$. The 4 measurements listed above were made on each sample. A second compartment (\#11) was then selected and the above procedures were repeated on the enclosed cultures at $2 \mathrm{~h}$ intervals for another $24 \mathrm{~h}$ period. In a second set of experiments, samples were taken from cultures in each of the 24 compartments on the 'wheel' at one time in the day (12:00 on each of 3 successive days). $P_{\max }$, cell numbers, chl $a$, and division stages were monitored for each culture for comparison with results obtained using the more conventional sampling protocol of experimental set 1 .

\section{Experimental methods}

Aliquots of Ditylum brightwellii cultures were fixed at each sampling time for quantitation of cell division stages. Fixing consisted of adding $0.25 \mathrm{ml}$ of a solution of $200 \mu \mathrm{g} \mathrm{ml}^{-1}$ acridine orange in concentrated $37 \%$ $(\mathrm{w} / \mathrm{v})$ calcium carbonate-buffered formaldehyde to each $5 \mathrm{ml}$ subsample of $D$. brightwellii culture in a $22 \mathrm{ml}$ glass scintillation vial. Prior to microscopic observation, preserved samples were concentrated onto $10 \mu \mathrm{m}$ Nitex netting, washed briefly in tap water, and transferred to a Zeiss settling chamber. Counting and identification of division stages were done at $200 \times$ magnification on a Leitz Diavert inverted microscope equipped with a $100 \mathrm{~W}$ mercury lamp for epifluorescence. The distinct stages we considered are described in Coats and Heinbokel (1982) and depicted in Fig. 2.

$\mathrm{P}_{\max }$ was measured as ${ }^{14} \mathrm{C}$-sodium bicarbonate
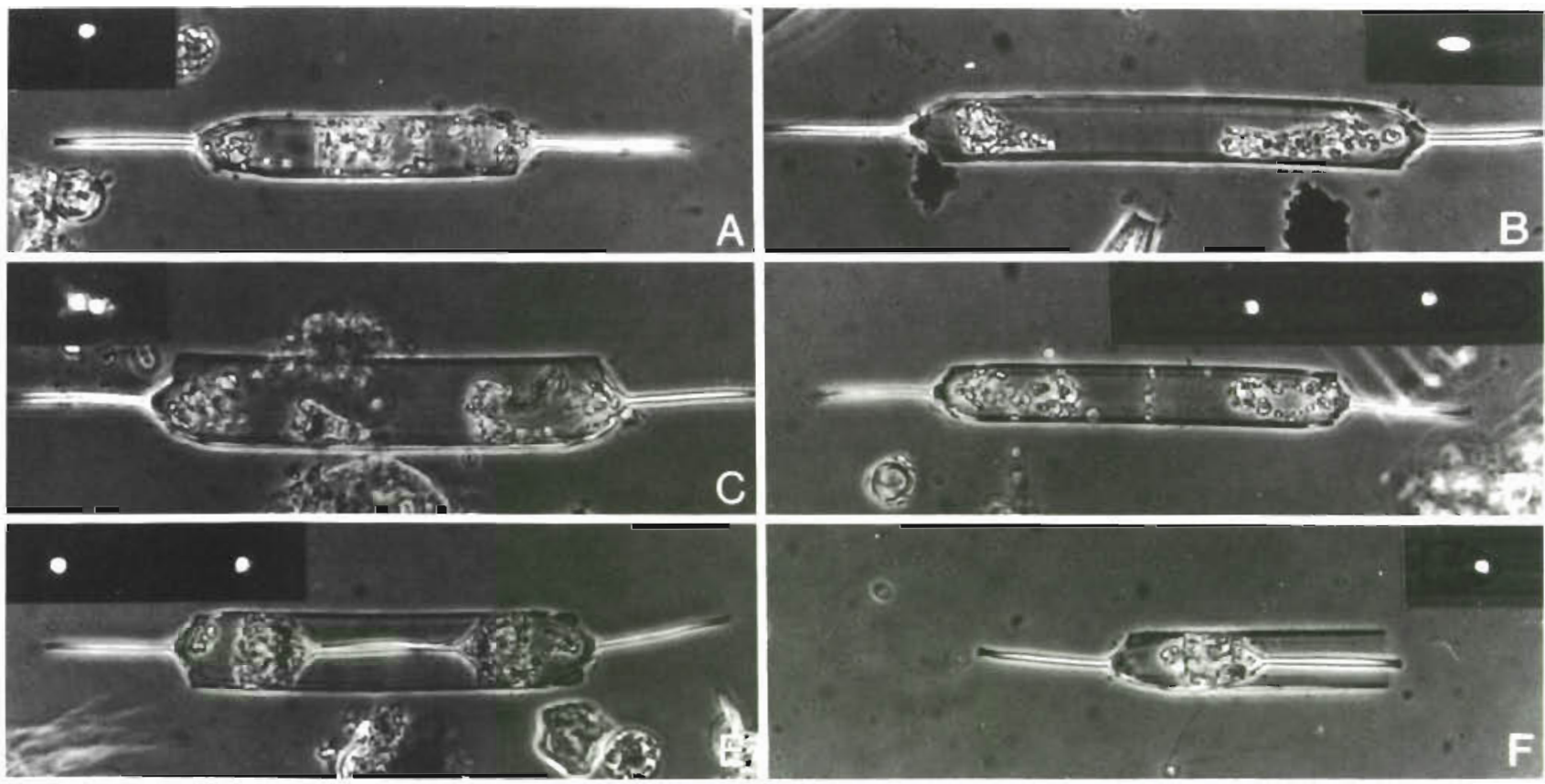

Fig. 2. Ditylum brightwellii. Cell division stages of non-dividing single cell (A), cell with elongated nucleus, commencing division sequence $(B)$, cell which does not appear to be dividing when observed under phase contrast, but whose nuclei have clearly replicated (C), nuclear and cytoplasmic separation (D), doublet cells beginning separation (E), recently divided single cell $(\mathrm{F})$. Cells depicted as seen in phase contrast illumination at a magnification of $230 \mathrm{X}$. Insets: same cells in combined phase contrast and acridine orange fluorescence 
assimilation at light saturation. Approximately $0.25 \mu \mathrm{Ci}{ }^{14} \mathrm{C}-\mathrm{NaHCO}_{3}$ (ICN Pharmaceuticals, Inc.) was added to each of three $5 \mathrm{ml}$ aliquots of Ditylum brightwellii culture in $22 \mathrm{ml}$ acid-washed glass scintillation vials. Two of these vials were incubated for $1 \mathrm{~h}$ at an irradiance of $150 \mu \mathrm{E} \mathrm{m}^{-2} \mathrm{~s}^{-1}$ and temperature of $15^{\circ} \mathrm{C}$, while the third sample was incubated in darkness for the same interval. Following incubation, cells were collected by gentle vacuum filtration (= $150 \mathrm{~mm} \mathrm{Hg})$ onto $25 \mathrm{~mm}$ diameter Gelman A/E glass fiber filters that were placed in liquid scintillation (LS) minivials in $3.5 \mathrm{ml}$ of toluene-based scintillation fluor. Activity was determined on a Packard Tri-Carb model 3320 LS counter. Photosynthetic carbon assimilation at lightsaturation was corrected for dark uptake of ${ }^{14} \mathrm{C}$ $\mathrm{NaHCO}_{3}$, and expressed as a function of a cell numbers and chl a concentration. Cell numbers were monitored on sample collected from each culture. Five ml of culture were withdrawn and fixed in Lugol's solution, and later counted on a Sedgwick-Rafter $1 \mathrm{ml}$ counting chamber using a Zeiss compound microscope. Chl a concentrations were determined fluorometrically using a Turner model 111 fluorometer equipped with a red-sensitive (R446) photomultiplier. Five ml of culture were collected by filtration onto a Whatman GF/F glass fiber filter, frozen at $-20^{\circ} \mathrm{C}$, and later extracted by grinding in 8 to $10 \mathrm{ml}$ of $90 \%$ acetone. The fluorometer was calibrated against a Beckman model DK-2 recording spectrophotometer using the equations of Jeffrey (1968, 1974) to calculate chl a from absorbances of $D$. brightwellii extracts and pure chl a (Sigma Chemical, Inc.) at 664 and $630 \mathrm{~nm}$.

\section{RESULTS AND DISCUSSION}

\section{Cell division}

Cell division showed diel periodicity when cultures were grown in a light environment with diurnal variations of intensity (Fig. 3). Ditylum brightwellii grown on the 'wheel' and sampled around-the-clock had a broad daytime peak in division, as measured by summing the percentages of recently divided cells, paired cells, and cells with dividing or paired nuclei (Fig. 3A). Individually phased cultures of $D$. brightwellii sampled from all 'wheel' compartments at a single time in the day showed the same pattern (Fig. 3B).

Expression of rhythmicity in cell division occurred in the varying intensity light regime much as in constant intensity regimes studied earlier (e.g. Eppley et al., 1967; Paasche, 1968; Chisholm et al., 1978). Chisholm (1981) summarized results of the many studies of diatom division rhythms, and suggested that the timing of cell division in this taxonomic group is not phase-restricted. That is, division can occur any time during the daylight cycle (and sometimes during the dark period), and is largely coupled to energy supply and cell cycle events related to synthetic pathways. Earlier, Chisholm et al. (1980) proposed that the flexibility in cell division patterns that typifies diatoms may reflect variability in the generation times of individual cells. Only severe treatments, such as growth with an extremely short photoperiod or exposure to a temporally narrow pulse of nutrients, are sufficient to induce phase-restricted or 'gated' division in diatoms. As suggested by Chisholm (1981), an advantage of this flexibility in division time may be related to the nature of the environment these cells occupy. Diatoms inhabit unstable environments, predominating in upwelling and coastal regions rather than in stable, tropical regions. The division pattern they exhibit is coupled and responsive to environmental change, with rhythms reflecting 'forced, rather than entrained oscillations' (Chisholm, 1981).

\section{Photosynthetic capacity}

Diel periodicity of light-saturated photosynthesis was detected for Ditylum brightwellii cultures grown in a light regime of varying intensity (Fig. 4). Oscillations in $P_{\text {max }}$ occurred both in single cultures sampled at $2 \mathrm{~h}$ intervals and in the set of phase-lagged cultures that was tested once per day. The general characteristics of time-dependent photosynthetic patterns were reproduced for both $\mathrm{P}_{\max }$ cell ${ }^{-1}$ and $\mathrm{P}_{\max }$ chl $a^{-1}$ using time-lagged replicates, although variations in carbon uptake rates among cultures were detected. The amplitude of diel oscillations ranged from approximately 3.0 to 5.2 for $P_{\max }$ cell ${ }^{-1}$, and 5.5 to 7.7 for $P_{\max }$ chl $a^{-1}$, as measured by the maximum to minimum ratios. Oscillations in $\mathrm{P}_{\max }$ cell $^{-1}$ were not simply related to a rhythm in chl a cell ${ }^{-1}$, as indicated by the occurrence of periodicity in light-saturated photosynthesis expressed as $P_{\max }$ chl $a^{-1}$ (Fig. 4 C,D), and the lack of phased oscillations in chl a cell-1 (Fig. 5). Populations of $D$. brightwellii cells appeared to anticipate the onset of the light period in that increases in $\mathrm{P}_{\max }$ cell ${ }^{-1}$ and $\mathrm{P}_{\max } \mathrm{chl} a^{-1}$ preceded subjective dawn $(=C T 0)$ by several hours. Since $D$. brightwellii is believed to have an endogenous rhythm in photosynthesis (Harding et al., 1981a), the finding of anticipatory physiological behavior is not surprising.

The time-dependent pattern in $P_{\max }$ for Ditylum brightwellii grown on a varying intensity $\mathrm{LD}$ schedule differed from results obtained earlier when this same diatom species was cultured at a single light intensity (compare Harding et al., 1981a): the peak in $\mathrm{P}_{\max }$ in the present study was broad as compared to the narrow 


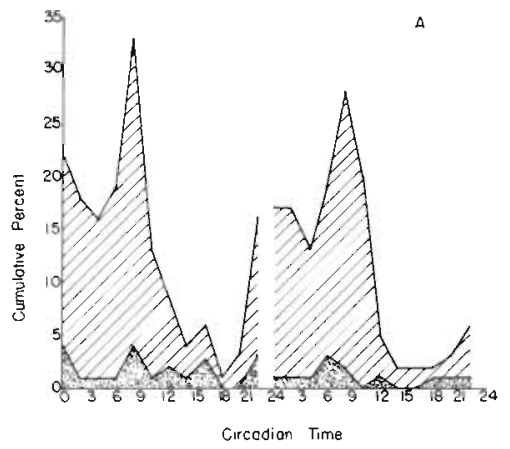

$B$

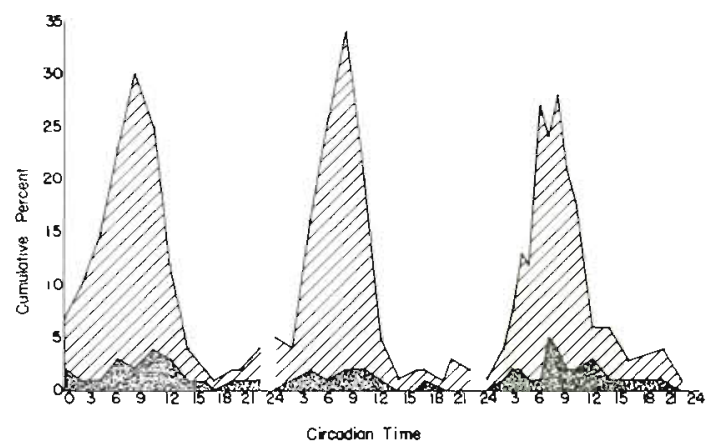

Fig. 3. Ditylum brightwellii. Diel periodicity of cell division measured as frequency of division stages in individual cultures sampled every $2 \mathrm{~h}$ (A), and in a set of phase-lagged replicate cultures (B); lined area: doublet cells plus one-half recently divided cells; dotted area: dividing cells or cells with paired nuclei
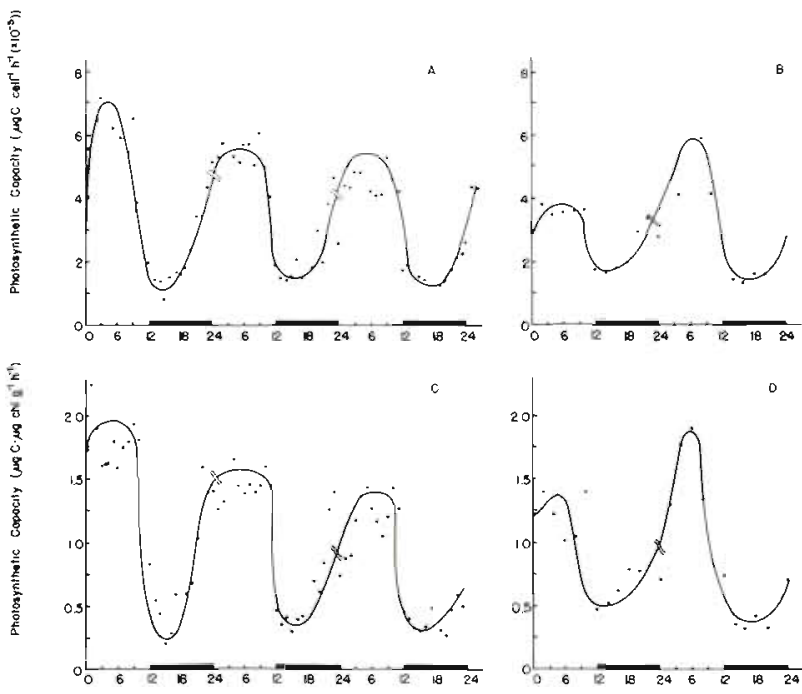

Fig. 4. Ditylum brightwellii. Periodicity of photosynthetic capacity $\left(\mathrm{P}_{\max }\right)$ on per cell and per chl a bases for phaselagged $(A, C)$ and individual cultures $(B, D)$

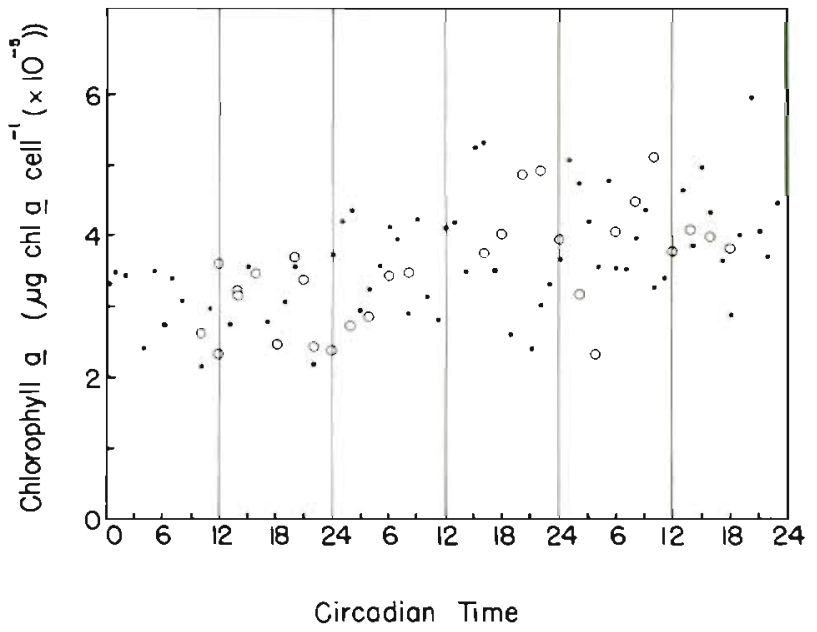

Fig. 5. Ditylum brightwellii. Chlorophyll a concentration per cell for phase-lagged $(\bullet)$ and individual cultures $(0)$ throughout experiment

peak in photosynthetic capacity described earlier. $\mathrm{P}_{\max }$ cell $^{-1}$ as a proportion of the maximum value attained during the light period was plotted for $D$. brightwellii grown in varying and constant intensity photic regimes (Fig. 6). The shapes of these plots differ: D. brightwellii maintained near-maximal photosynthetic capacity throughout the daylight hours when grown in a light supply that varies in intensity, but showed largeamplitude changes when grown on a single-intensity LD cycle.

The implications of this finding are significant. In Ditylum brightwellii and many other phytoplankton species, $\alpha$ (initial slope of the P-I relationship), and $\mathrm{P}_{\text {max }}$ (asymptote) are highly correlated (cf. MacCaull and Platt, 1977; Harding et al., 1982a, 1983; Cöté and Platt, 1983). Cells grown on a light cycle with diurnally varying intensity, unlike those grown on constant, saturating intensities, experience light levels during at least some parts of the day that are less than required to saturate photosynthesis and growth. At these subsaturating irradiances, cells operate in the lightlimited portion of P-I curves. The slope, $\alpha$, describes the rate of carbon assimilation at subsaturating light intensities. Since this parameter changes in synchrony with changes in $P_{\max }$ (see Harding et al., 1981b), maintenance of near-maximal $P_{\max }$ over much of the day indicates that $\alpha$ is also maintained at a higher value in the varying than in the constant light condition (Fig. 6 A,B). This results in enhanced carbon assimilation at suboptimal light intensities. In contrast, cells grown at a constant irradiance on LD 12:12, saturating for both photosynthesis and growth rate, showed a morning maximum in $\mathrm{P}_{\max }$, but a later depression to submaximal values that commenced prior to midday. The amplitude of changes in $\mathrm{P}_{\max }$ in 

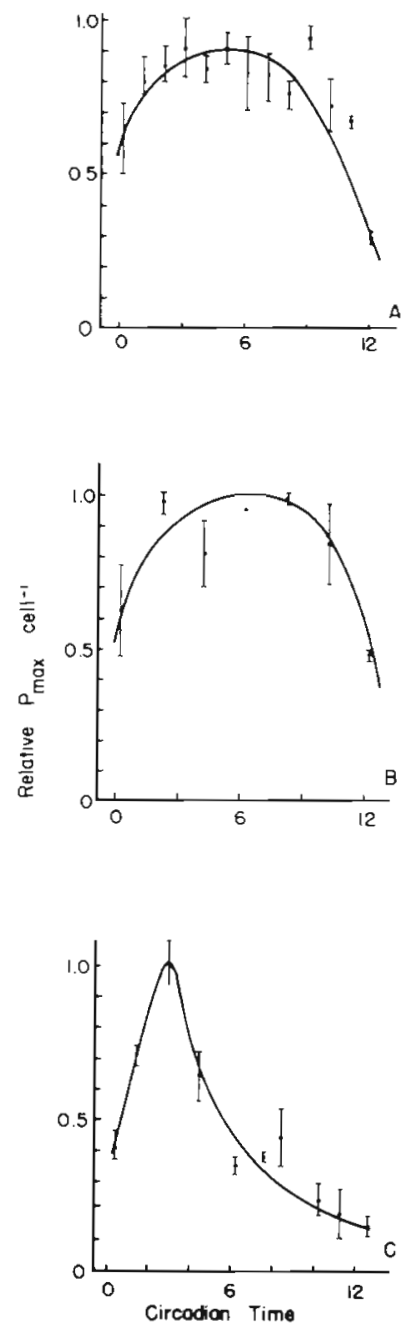

Fig. 6. Ditylum brightwellii. $\mathrm{P}_{\max } \mathrm{cell}^{-1}$ as a proportion of the maximum photosynthesis rate attained during the day $\left(=\right.$ relative $\left.P_{\max }\right)$ for phase-lagged replicate cultures $(A)$ and individual cultures sampled at $2 \mathrm{~h}$ intervals (B) grown on a varying intensity light supply, and for individual cultures grown on a constant intensity light supply (C) (adapted from Harding et al., 1981a)

the daylight hours of the LD cycle was large, but there was still sufficient carbon assimilation during the day to support a maximal growth rate. These findings suggest that the rate at which saturating light levels are attained during the day, as well as the total amount of light available, will serve to control the pattern of photosynthetic periodicity.

The selective advantage of such a mechanism for responding to quantitative light signals could be associated with the amount of light necessary to promote a maximal growth rate. By maintaining photosynthetic carbon uptake at a comparatively high level throughout the day, as in this varying photic environment, cells may optimize fixation of carbon in a suboptimal photic regime. In the present study, this occurs because photosynthetic efficiency in low light, described by $\alpha$, would be enhanced in morning and afternoon hours when subsaturating irradiances were experienced. In contrast, a constant saturating light environment does not provide the stimulus to enhance light-limited or light-saturated rates of carbon fixation since a saturating supply of photic energy is available throughout the light period. Thus, $\alpha$ and $P_{\max }$ can undergo large amplitude oscillations without resulting in reduced integral photosynthetic performance $\left(\int P_{i}=\right.$ total daily carbon fixation in ambient light conditions).

If the explanation offered above for differences in carbon fixation in distinct photic regimes is correct, it would be expected that patterns of $\int \mathrm{P}_{1}$ would differ. To test the validity of this explanation, we calculated $\int P_{1}$ from data obtained in the present study where Ditylum brightwellii was cultured in a varying light regime, and also from results of experiments in light of a constant intensity that were published earlier (Harding et al., 1981a). This approach required estimating lightlimited photosynthesis from the light-saturated rate, using the strong correlation between $\alpha$ and $P_{\max }$ that has been described for this and other species (cf. Harding et al., 1981a, 1983; Cöté and Platt, 1983; Prézelin, 1983). Combining the time-series of derived P-I curve parameters ( $\alpha$ and $P_{\max }$ ) with data for light intensity at different times of day produced estimates of $P_{1}$. Summing these estimates over the day gave the value for $\int \mathrm{P}_{i}$, which has been plotted as cumulative $\mathrm{P}_{\mathrm{i}}$, or $\int_{0}^{t} \mathrm{P}_{1}$, where $t=$ the time of day to which carbon fixation is summed (Fig. 7).

Using this approach, the explanation appears both plausible and testable, as evidenced by the daily patterns of carbon assimilation for Ditylum brightwellii in the 2 photic regimes (Fig. $7 \mathrm{~A}, \mathrm{~B}$ ). In the light regime of varying intensity, $P_{i}$ was principally controlled by the light supply, reaching a maximum in midday when light intensities were maximal. $P_{1}$ in the constant intensity photic regime, however, reached a peak early in the day. A decrease in $\mathrm{P}_{\mathrm{i}}$ later in the day (post-CT 3) reflected the physiological change, i.e. the middayafternoon decrease in $\mathrm{P}_{\max }$ depicted in Fig. 6B. $\int \mathrm{P}_{\mathrm{i}}$ over the daylight hours (cumulative to CT 12) was approximately equivalent in these 2 light regimes, suggesting that the 'physiologically' controlled changes in $P_{1}$, as in the constant I regime, and 'environmentally' controlled changes, as in the varying I regime, will give the same $\int P_{i}: \int I$, provided that the 2 light regimes supply equivalent amounts of photic energy. In comparing these relationships (Fig. $7 \mathrm{~B}$ ), the fact that $\int \mathrm{P}_{2}: \int \mathrm{I}$ was higher in the constant than in the varying light regime can be explained by the greater total light supplied to cultures grown on varying light (5.38 vs. $4.19 \mathrm{E} \mathrm{m}^{-2} \mathrm{~d}^{-1}$ ).

It should be noted that both amounts of light were sufficient to promote a maximal growth rate $\left(\mu_{\text {cell }}=\right.$ 

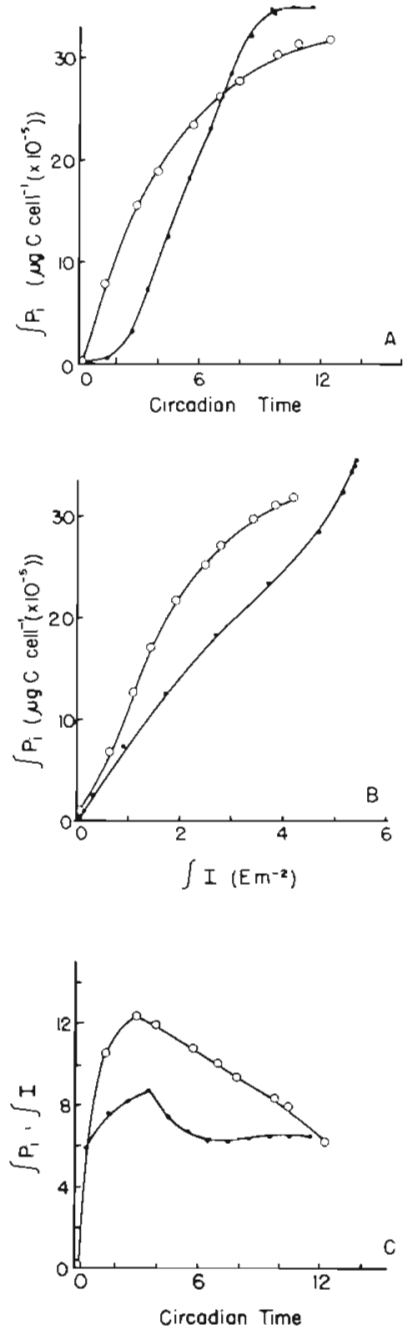

Fig. 7. Ditylum brightwellii. Integral photosynthetic performance $\left(\int P_{1}\right)$ as a function of circadian time $(A), \int P_{j}$ vs. integral light supplied during the course of the photoperiod (B), and $\int \mathrm{P}_{\mathrm{i}}: \int \mathrm{I}$ vs. circadian time (C) for cells grown on the light supply of varying $(\bullet)$ or constant intensity $(O)$. In situ carbon fixation $\left(P_{i}\right)$ was integrated over time from dawn through the day (CT $=0$ to $C T=t$ ), and represents cumulative photosynthetic performance as a function of light loading during the specified interval

$.88 \pm .04 \mathrm{~d}^{-1} ;$ gen. time $=1.14 \mathrm{~d}, 15^{\circ} \mathrm{C}$ ). Attention, therefore, should be focused on the shapes of the functions: a comparison of curve shapes demonstrates that carbon fixation per unit available light in the condition of varying intensity was less variable than was this function in growth at a constant, saturating light intensity (see Fig. 7C). The 'physiological' contribution to a change in $\mathrm{P}_{\mathrm{i}}$ as a function of I was apparent, however, even in the varying light regime, as demonstrated by the increased $\int \mathrm{P}_{\mathrm{i}}: \int \mathrm{I}$ in the morning hours. The complete set of plots (Fig. 7 A-C) confirms that light energy was not harvested at equal efficiency throughout the day by Ditylum brightwellii populations exposed to the single, saturating light intensity. In the varying light regime, encompassing both light-limited and light-saturated regions of the P-I relationship, carbon fixation per unit light showed an underlying periodicity, but control of changes in $\mathrm{P}_{\mathrm{i}}$ was largely related to changes in $\mathrm{I}$. This finding suggests that $D$. brightwellii optimized its pattern of carbon assimilation in each photic regime to maintain a maximal growth rate.

Data for light utilization by the centric diatom Lauderia borealis grown in a natural sunlight cycle are consistent with our findings (Marra and Heinemann, 1982). L. borealis showed a morning maximum and an afternoon depression in photosynthesis $\left(\mathrm{P}_{\mathrm{i}}\right)$ on sunny days when presumably photosynthesis was light-saturated early and for much of the day (see also Harding et al., 1981a), whereas changes in the photosynthetic rate were closely coupled to changes in irradiance on cloudy days. Rapid variations in sunlight intensity (minutes) superimposed on the diurnal cycle of variability had little or no effect on the overall pattern of photosynthesis, and the pattern that emerged appeared related to diel oscillations in the P-I relationship, and to the total amount of light available. Thus, the argument against the use of constant light intensities in studying periodicity or photoadaptation is strengthened by the present findings and by those of Marra and Heinemann (1982) for the reasons that such regimes poorly mimic nature and can, as both studies indicate, produce responses unique to artificial culture conditions. It also appears that much of the variation in $P_{1}$ can be explained simply by considering timedependence of the photosynthesis-light relationship of L. borealis. These rhythms in P-I relationships could aid in interpreting diel patterns of $P_{1}$ in the field or in 'greenhouse' experiments such as those of Marra and Heinemann (1982). This viewpoint is consistent with the continuing use of the P-I relationship in models of primary productivity.

\section{CONCLUSIONS}

Use of phase-lagged replicate cultures of Ditylum brightwellii obtained by offsetting subjective dawn at successive $1 \mathrm{~h}$ intervals is a convenient method for studying rhythmicity and has been shown to provide equivalent data as standard but more tedious repetitive sampling of a single culture. Under the conditions of diurnally varying light used in this experiment, $D$. brightwellii exhibited a relatively broad temporal peak in reproduction during daylight hours. Photosynthetic capacity, $P_{\max }$, also displayed a broad daytime maximum during the daylight hours when $D$. brightwellii was grown with a diurnally varying light 
supply. Previous studies utilizing a constant, saturating light supply during the daylight hours (Harding et al., 1981a) resulted in a quite different diel pattern of $P_{\text {max }}$, one that was characterized by a sharp morning peak, with greatly lowered values later in the daylight hours. It appeared that the response of the D. brightwellii cultures exposed to more natural conditions of diurnally varying light was to maximize photosynthetic capacity during the subsaturating portions of the daylight hours. This would appear to be a highly beneficial physiological adaptation for natural populations normally exposed to such varying, and often unpredictable, light regimes. Great care, therefore, must be used in interpreting laboratory-derived patterns of photosynthesis and in extrapolating or applying those patterns to natural populations and assemblages.

Acknowledgements. We thank L. Brice, Dr. D. Coats, K. Henderson. M. Mallonee, E. Schiemer, and R. Whaley of CBI for assistance on various aspects of this study. Stimulating discussions of these results with Drs. H. Seliger and M. Tyler are gratefully acknowledged. Partial support of this research was provided by an award from the Maryland Sea Grant Program (NOAA) to L.W.H.

\section{LITERATURE CITED}

Chisholm, S. W. (1981). Temporal patterns of cell division in unicellular algae. In: Platt, T. (ed.) Physiological bases of phytoplankton ecology. Can. Bull. Fish. aquat. Sci. 210: 150-181

Chisholm, S. W., Azam, F., Eppley, R. W. (1978). Silicic acid incorporation in marine diatoms on light/dark cycles: use as an assay for phased cell division. Limnol. Oceanogr. 23: 518-529

Chisholm, S. W., Morel, F. M. M., Slocum, W. S. (1980). The phasing and distribution of cell division cycles in marine diatoms. In: Falkowski, P. G. (ed.) Primary productivity in the sea. Brookhaven Press, New York, p. 281-300

Coats, D. W., Heinbokel, J. F. (1982). A study of reproduction and other life cycle phenomena in planktonic protists using an acridine orange fluorescence technique. Mar. Biol. $67: 71-79$

Cöté, B., Platt. T. (1983). Day-to-day variations in the springsummer photosynthetic parameters of coastal marine phytoplankton. Limnol. Oceanogr. 28: 320-344

Doty, M. S. (1959). Phytoplankton photosynthesis periodicity as a function of latitude. J. mar. biol. Ass. India 1: 66-68

Eppley, R. W., Holmes, R. W., Paasche, E. (1967). Periodicity in cell division and physiological behavior of Ditylum brightwellii a marine plankton diatom, during growth in light-dark cycles. Arch. Mikrobiol. 56: 305-323

Guillard, R. R. L., Ryther, J, H. (1962). Studies of marine planktonic diatoms. I. Cyclotella nana Hustedt and Detonula confervacea (Cleve) Gran. Can. J. Microbiol. 8: $229-239$

Harding, L. W., Jr., Meeson, B. W., Prézelin, B. B., Sweeney, B. M. (1981a). Diel periodicity of photosynthesis in marine phytoplankton. Mar. Biol. 61: 95-105

Harding, L. W., Jr., Meeson, B. W., Tyler, M. A. (1983). Photoadaptation and diel periodicity of photosynthesis in the dinoflagellate Prorocentrum mariae-lebouriae. Mar. Ecol. Prog. Ser. 13: 73-85

Harding, L. W., Jr., Prézelin, B. B., Sweeney, B. M., Cox, J. L. (1981b). Diel oscillations in the photosynthesis-irradiance relationship of a planktonic marine diatom. J. Phycol. 17: 389-394

Harding, L. W., Jr., Prézelin, B. B., Sweeney, B. M., Cox, J. L. (1982a). Diel oscillations of the photosynthesis-irradiance $(P-I)$ relationship in natural assemblages of phytoplankton. Mar. Biol. 67: 167-178

Harding, L. W., Jr., Prézelin, B. B., Sweeney, B. M., Cox, J. L. (1982b). Primary production as influenced by diel periodicity of phytoplankton photosynthesis. Mar. Biol. 67: 179-186

Jeffrey, S. W. (1968). Quantitative thin-layer chromatography of chlorophylls and carotenoids from marine algae. Biochim. biophys. Acta 162: 265-270

Jeffrey, S. W. (1974). New spectrophotometric equations for determining chlorophylls $a, b, c_{1}$, and $c_{2}$ in phytoplankton and higher plants. Rep. mar. Biochem. Unit C.S.I.R.O. 1974:6-8

MacCaull, W. A., Platt, T. (1977). Diel variations in the photosynthetic parameters of coastal marine phytoplankton. Limnol. Oceanogr. 22: 723-731

Malone, T C. (1971). Diurnal rhythms in netplankton and nannoplankton assimilation ratios. Mar. Biol. 10: 285-289

Marra, J., Heinemann, K. (1982). Photosynthesis responses by phytoplankton to sunlight variability. Limnol. Oceanogr. 27: 1141-1153

Nelson, D. M., Brand, L. E. (1979). Cell division periodicity in 13 species of marine phytoplankton on a light/dark cycle. J. Phycol. 15: 67-75

Paasche, E. (1968). Marine plankton algae grown with light/ dark cycles. II. Ditylum brightwellii and Nitzschia turgidula. Physiol. Plant. 21: 66-77

Prézelin, B. B. (1983). Effects of light intensity on aging of the dinoflagellate Gonyaulax polyedra. Mar. Biol. (in press)

Prézelin, B. B., Ley, A. C. (1980). Photosynthesis and chlorophyll a fluorescence rhythms of marine phytoplankton. Mar. Biol. 55: 295-307

Prézelin, B. B., Meeson, B. W., Sweeney, B. M. (1977). Characterization of photosynthetic rhythms in marine dinoflagellates. I. Pigmentation, photosynthetic capacity and respiration. Pl. Physiol. 60: 384-387

Richman, S., Rogers, J. N. (1969). The feeding of Calanus helgolandicus on synchronously growing populations of the marine diatom Ditylum brightwellii. Limnol. Oceanogr. 14: 701-709

Sournia, A. (1974). Circadian periodicities in natural populations of marine phytoplankton. Adv. mar. Biol. 12 325-389 